Accelerator Division

Alternating Gradient Synchrotron Department

BROOKHAVEN NATIONAL LABORATORY

Upton, New York 11973

Accelerator Division

Technical Note

AGS/AD/Tech. Note No. 345

\title{
RECOMMISSIONING AN UPGRADED POLARIZED BEAM FACILITY
}

L.G. Ratner

November 1, 1990

\section{Summary}

We envision a three-phase project beginning with the immediate construction of a partial "Siberian snake" and culminating with $24.8 \mathrm{GeV} / \mathrm{c}$ injected polarized proton beams in RHIC.

\section{Phase 1}

Construct and install a partial snake. Appendix 7 is an AIP proposal at a cost of $\$ 124,000$, which starts January, 1991 and finishes october, 1992. Concurrently, maintenance and repair of the fast quad modulators (Appendix 2) at a hardware cost of $\$ 25,000$ is accomplished. Depending on power supply availability, we would expect to test at energies between 10 and $22 \mathrm{GeV}$.

\section{Phase 2}

Reconfigure the fast quad modulator system to be able to reach RHIC injection energy at a hardware cost of $\$ 44,000$ (Appendix 5). For tests of polarization survival, AGS extraction and transfer to RHIC, we will require some instrumentation and a polarimeter at the end of the transfer line. Could be scheduled for testing in AGS by October, 1993. 


\section{Phase 3}

Installation of RHIC snakes and polarimeter at a cost of \$4.8M (Appendix 6). Booster commissioning to reach higher polarized proton intensities if not already accomplished. Will also need the polarized proton tune quad power supplies. Appendix 3 is an AIP proposal for these quad power supplies at a cost of $\$ 301,000$ which could be done as part of Phase 2 or Phase 3. To go from $\mathrm{P}_{f} / \mathrm{P}_{i}=40-50 \%$ to $\mathrm{P}_{f} / \mathrm{P}_{i}=90-100 \%$ will require a new power supply $(12.6 \mathrm{kA}, 230 \mathrm{~V})$ similar to the MPS supply (16 kA, $260 \mathrm{~V})$. This supply has not been included in the cost of the project.

$\underline{\operatorname{cosT}}$

Phase $1 \$ 149 \mathrm{~K}$

Phase $2 \quad \$ 44 \mathrm{~K}$ or $\$ 345 \mathrm{~K}$

Phase $3 \quad \$ 4.8 \mathrm{M}$ or $\$ 5.1 \mathrm{M}$
READY FOR

AGS/RHIC TESTS

Oct. 1992 (FY91 \$50K; FY92 \$100K)

oct. 1993 (FY93 \$345K)

Oct. 1996 (FY94 \$2M; FY95 \$1.9M; FY96 $\$ 0.9 \mathrm{M})$

Phase 3 costs do not include experimental detectors nor any new experimental facilities, but does include a polarimeter in RHIC.

The AGS could be used for HEP experiments with polarized beam as soon as the partial snake is commissioned. This could be accomplished by December, 1992.

The following bar charts represent a doable scenario. Phase 1 is rather solid, Phase 2 requires further consideration of RHIC transfer line instrumentation, and Phase 3 requires much more work and probably more money for a complete operating system. The given time frame, however, does seem adequate. 


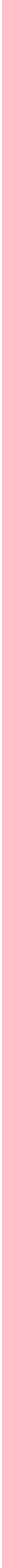




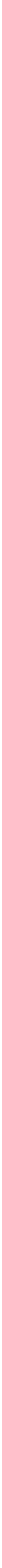





\section{RECOMMISSIONING AN UPGRADED POLARIZED BEAM FACILITY}

As evidenced by the activities of some dozen laboratories around the world, there is a great deal of interest in spin physics. Basically, we see that spin physics experiments are producing challenges to $P Q C D$ that have as yet not been answered. Spin may indeed lead to a more complete theory, just a it was an essential ingredient in QED, a calculable theory with unsurpassed success. Today, we have no theoretical explanation of hyperon polarization, no convincing picture of the spin structure of the nucleon, and no ideas of why the analyzing power in protonproton elastic scattering should be large at high energy and high transverse momentum. These are only a few of the items that are being further explored by on-going experiments. It is also thought that spin in the proposed higher energy machines will provide important tests of standard model predictions as well as giving distinctive signatures for new physics. Physics ideas of exploiting spin to study the strong and weak interactions will be explored at the November, 1990, Polarized Collider Workshop at Pennsylvania state University. Clearly, the first collider available for such tests is RHIC.

The recent history of spin physics is closely tied to the state-of-the-art accelerator physics with the resonancejumping tests developed for the ZGS and AGS and the development of Siberian snakes, first tried at IUCF. The AGS is the next logical place after the Indiana University Cyclotron Facility to continue the study of siberian snakes. At IUCF, we demonstrated that one could use a snake to cross both an imperfection and an intrinsic resonance. The AGS will allow us to study the behavior of snakes in crossing many resonances as well as other aspects which should be demonstrated before such devices are incorporated into accelerators like the SSC. 
It, therefore, seems appropriate that we again prepare to accelerate polarized protons in the AGS with a snake and prepare the AGS to be a suitable injector for RHIC. We view this program as a sequence of several phases that will culminate with a successful injector and a polarized beam capability in RHIC.

The steps necessary to arrive at polarized protons in RHIC have become clear:

1. The Booster/Accumulator provides a high polarized proton luminosity for the AGS and RHIC.

2. A partial Siberian snake in the AGS will maintain polarization up to RHIC injection energy.

3. An injection momentum of $24.8 \mathrm{GeV} / \mathrm{c}$ avoids a spin resonance in the transfer line and is above RHIC transition energy.

4. Two Siberian snakes per ring will be needed in RHIC; these snakes can be distributed around intersection regions to provide the dual function of maintaining the polarization and preparing longitudinal spins for experiments.

5. By box-car stacking the polarized protons in RHIC, alternate bunches can have opposite polarization. This will largely eliminate systematic errors for the experiments.

\section{Phase 1}

In this phase, we address the major problem of the long tune-up time needed to run polarized protons in the AGS. From 
past experience, it would take two to three weeks to obtain a high energy polarized beam. This can be reduced to 2-3 days by the use of a siberian snake. Based on the experiments at the Indiana University Cyclotron Facility cooler Ring and on our calculations of the effects in the AGS, we have a conceptual design for a Partial snake solenoid (Appendix 2) that can give us a polarized beam up to the RHIC injection energy of $24.84 \mathrm{GeV} / \mathrm{C}$ $(G \gamma=47-1 / 2$, which is an energy that preserves polarization in going through the RHIC transfer line).

This phase then consists of the following steps:

1. Engineering design and construction of a partial snake solenoid. Installation with a power supply suitable for initial testing.

2. Perform the necessary maintenance for the fast pulsed quadrupole power supplies. The necessary effort is outlined in Appendix 2.

3. Reinstall the $200 \mathrm{MeV}$ and internal polarimeters and check operation and communications to the Main Control Room.

4. Plan to use the normal tune quads and bipolar supplies for a slow tune shift until we obtain suitable power supplies for the new polarized proton slow tune quads (Appendix 3).

5. Install a suitable power supply for the snake. A choice can be made from the table in Appendix 4. There are 2.4 $\mathrm{kA}, 4.8 \mathrm{kA}$ supplies in the AGS inventory. $9.5 \mathrm{kA}$ can be reached with two $4.8 \mathrm{kA}$ supplies in parallel. Power supplies for RHIC physics operation will probably have to be procured. 
With these steps completed, we would begin machine studies of a few days (3-4) at a time addressing the effects of adiabatic turn-on and turn-off of the snake, the efficiency in passing through imperfection resonances, the interaction, if any, with the fast tune corrections and with transition, and to study the stable spin direction in the AGS. As in the past, new phenomena may occur. Phase 1 could proceed in stages of increasing current availability to the snake solenoid by starting with $2.4 \mathrm{kA}$ and then to $4.8 \mathrm{kA}$ and $9.6 \mathrm{kA}$. This would give momentum limits of about 10,18 , and $22-1 / 2 \mathrm{GeV} / \mathrm{C}$ for the three ranges.

\section{Phase 2}

This phase prepares the AGS to reach RHIC injection energy. Tests of the AGS extraction and transfer to RHIC can also be made. The essential steps and hardware are as follows:

1. The fast quad power supply system must be re-arranged so that we can provide a pulse to cross the $36+\nu$ intrinsic resonance. The effort and cost are in Appendix 5.

2. We must have at least the $9.5 \mathrm{kA}$ power supply to reach $24.8 \mathrm{GeV} / \mathrm{C}\left(\mathrm{P}_{\mathrm{f}} / \mathrm{P}_{\mathrm{I}} \approx 40-50 \%\right)$.

3. A polarimeter at the RHIC end of the transfer line would be desirable, but not absolutely necessary at this stage. Should probably measure both $\mathrm{P}_{\mathrm{H}}$ and $\mathrm{P}_{\mathrm{V}}$.

4. Again, one would expect better polarization survival if the power supplies of Appendix 3 were available, but again not absolutely necessary.

5. Some instrumentation in the RHIC transfer line. 
With the above in place, we again would need periods of a few days to achieve $24.8 \mathrm{GeV} / \mathrm{c}$, extract, and transfer to RHIC.

\section{Phase 3}

This phase covers RHIC operation. Given that all of the above steps are completed, this stage requires:

1. A power supply capable of reaching 11.2 or $12.5 \mathrm{kA}$ giving a $P_{f} / P_{i}$ of $80-90 \%$ (including anticipated intrinsic resonance depolarization).

2. Design, construction, installation, and tests of RHIC snakes (Appendix 6).

3. A RHIC polarimeter that can measure $\mathrm{P}_{\mathrm{V}}$ and $\mathrm{P}_{\mathrm{H}}$.

4. Commissioning of Booster to reach higher $P \uparrow$ intensity. This could be done during any phase.

Studies can then be made in RHIC on snake behavior, spin rotation, polarization reversal, and polarization survival.

\section{Acknow ledgment}

I would like to thank Leif Ahrens and Gerry Bunce for their valuable comments. 


\section{APPENDIX 1}

\section{PARTIAI SNAKE SOLENOID DESIGN}

This version uses $15 \%$ more current than the design in BNL-44886 but does not invalidate any conclusions from the previous calculations.

Using OTOKUMPO METALS \#6310 $29 \mathrm{~mm} \times 29 \mathrm{~mm} \times 16.2 \phi$ with $0.02 "$ insulation wrap, we can get 76 turns per layer in 90". Use four layers, 304 turns.

COIL CROSS-SECTION

4 LAYERS, SHOWING ONE OF 76 TURNS NOT TO SCALE

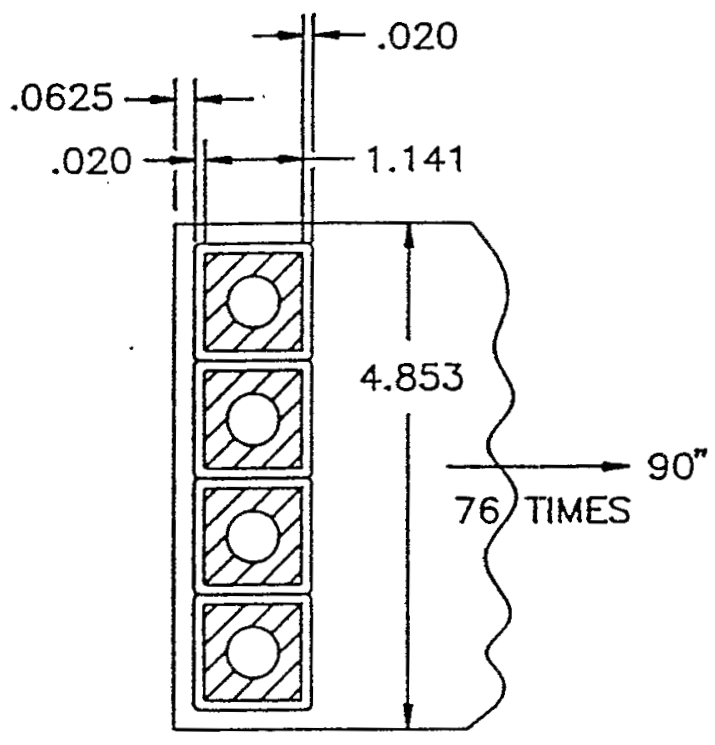

SOLENOID END VIEW

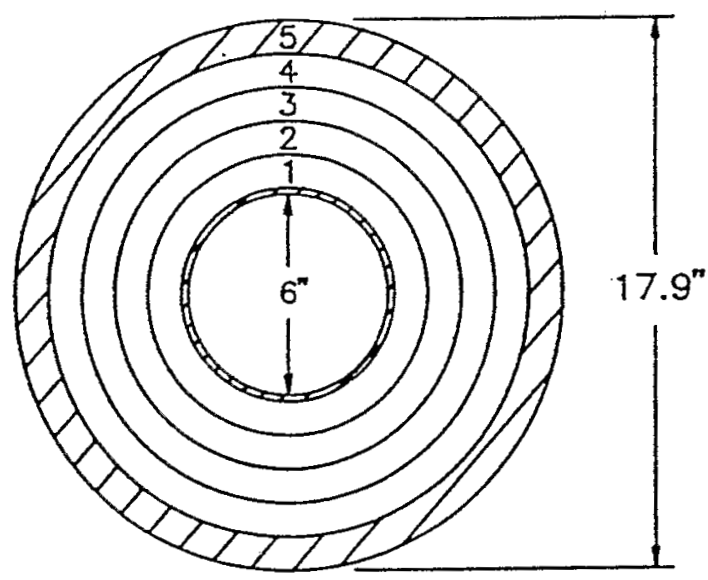

$\# 1$. \#2, \#3, \#4 LAYERS OF COPPER \#5 1" Fe RETURN PATH $\mathrm{B}_{\mathrm{Fe}} \sim 11 \mathrm{Kg}$

Schematic of coil and end view--not to scale. 


$$
\begin{aligned}
& \text { liongest layer }=260.4^{\prime}, \quad l \text { shortest layer }=174.9^{\prime}, \\
& \bar{l}=204.15^{\prime}, \bar{l}_{\text {total }}=4 \times 204.15=817^{\prime} \\
& R_{\text {longest layer }}=2.2 \mathrm{~m} \Omega, \mathrm{R}_{\text {Shortest layer }}=1.28 \mathrm{~m} \Omega \\
& \bar{R}=1.76 \mathrm{~m} \Omega, \bar{R}_{\text {total }}=7.04 \mathrm{~m} \Omega
\end{aligned}
$$

$$
\begin{aligned}
& \mathrm{L}=\frac{0.32 \mathrm{a}^{2} \mathrm{n}^{2}}{6 \mathrm{a}+9 \mathrm{~b}+10 \mathrm{c}} \mu \mathrm{H}, \text { where } \mathrm{a}=13.943 \mathrm{~cm} ; \mathrm{n}=304 \text { turns; } \\
& \mathrm{b}=228.5 \mathrm{~cm} ; \mathrm{c}=12.327 \mathrm{~cm} \\
& \mathrm{~L}=5.65 \mathrm{mH}
\end{aligned}
$$

An $8^{\circ}$ snake would use $11.2 \mathrm{kA}$ and a $9^{\circ}$ snake $12.6 \mathrm{kA}$ at 24.8 $\mathrm{GeV} / \mathrm{c}$. We will check the electrical and cooling performance for $12.6 \mathrm{kA}$.

1. Cooling Requirements

Ramp power supply in $0.6 \mathrm{sec}$ to $12.6 \mathrm{kA}$

$\therefore \quad$ Average current $\sim 6.3 \mathrm{kA}$

Voltage longest turn $=14.2 \mathrm{~V}$

Duty cycle is $0.6 \mathrm{sec} / 3 \mathrm{sec}=0.2$

$\therefore$ Power $_{\text {longest }}$ turn $=6.3 \times 14.2 \times 0.2=89.46 \times 0.2 \approx$ $18 \mathrm{KW}$.

Keep temperature rise to $10^{\circ}$, requires 6.8 GPM. Total length of four layers $=817^{\prime}$ with $d=0.638^{\prime \prime}$. Pressure required for $6.8 \mathrm{GPM}$ is 


$$
\Delta \mathrm{P}=\frac{817}{100} \times 4.84 \times 10^{-2} \frac{6.8^{1.85}}{0.638^{4.8655}}=122 \mathrm{PSI}
$$

Total average power $\overline{\mathrm{R}_{\mathrm{T}} \mathrm{I}^{2}} \times 0.2=7.04 \times 6.3 \times 0.2$.

$P_{\text {total }} \approx 57 \mathrm{KW} \Rightarrow \Delta \mathrm{T}=31^{\circ} \mathrm{C}$ in whole magnet.

2. Voltages required are shown in Appendix 4 .

These requirements are certainly feasible. 


\section{APPENDIX 2}

\section{FAST QUAD MODULATOR REPAIR AND UPGRADE}

\section{Task Description}

New Ceramic Tube Cap Assemblies

Inspect/Repair Carborundum Resistor

Assemblies

Repair/Calibrate Hillman Chassis

Inspect KV71 Trigger Tubes

New BNC Test Points on KV17/71 Chassis

Complete Automatic current Adjust (PEIs)
Man Hours

30

38

160

15

75

398 Hrs.

(a) 25 hours/week $\Rightarrow 16$ man weeks

\section{SPARE PARTS REQUIRED}

20 Trigger Thyratron Tubes

2 Power Thyratrons

5 Ignitrons

5 Resistor Assemblies

Misc. Components
$\$ 6,000$

4,000

10,000

500

$\underline{5,000}$

$\$ 25,500$

Total

Procurement and work accomplished between october, 1991 and July, 1992. 


\title{
APPENDIX 3
}

(Phase 2 or 3 )

\author{
BROOKHAVEN NATIONAL LABORATORY \\ PROPOSAL FOR ACCELERATOR IMPROVEMENTS
}

Polarized Proton tune quad Power supplies

\section{Basis}

The AGS accelerator requires a larger tune shift than is normally acceptable in order to pass through the intrinsic depolarizing resonances. In order to accomplish this, the power supplies in this project allow a slow shift in the opposite direction to compensate for the fast shift.

\section{Description}

The twelve correction quadrupoles located in the \#3 straight sections will be powered in pairs by six power supplies located in the equipment houses at ground level. Cables for each pair will come down the \#18 straight section conduit and feed to the \#3 straight sections on either side. Each power supply will be a $60 \mathrm{Amp}, 300 \mathrm{~V}$ dc unit which will charge a fast capacitive discharge circuit to give a fast rise time of 3 milliseconds. The system will be interfaced to the Apollo control system and will be similar to the system designed for the fast gamma transition jump.

\section{Justification}

The large fast tune shift would blow up the beam in the AGS. It, therefore, becomes necessary to limit it to a value of 0.2 or less which is accomplished by the above described power supplies.

\section{Analysis of Safety and Pollution}

There are no potential pollution problems or explosion risks associated with this project, other than those common to high power electrical equipment installation. Fire hazards are also limited to the usual risks inherent with electrical cables and equipment. The electrical installation will be designed and installed to meet or exceed the current national standards and safety codes.

All work will be in accordance with DOE order $5480.1 \mathrm{~B}$ "Environmental Protection, Safety and Health Protection Standards", DOE 6430.1A, General Design Criteria Manual, and BNL's Safety Manual. 
5. Cost Estimate
A. Engineering a approx. $10 \%$ of
Procurements, Assembly,
Installation \& Testing
B. Procurements
Power Supplies
Cables
Controls
Bridges
$\$ 40,000$
30,000
18,000
74,000
$\$ 162,000$
C. Assembly, Installation,
and Testing
$\$ 80,000$
D. Quality Assurance a 3\% of
Project cost
$\$ \quad 8,000$
E. Contingency @ $10 \%$ of
Project cost
$\$ 27,000$
TOTAL PROJECT COST
$\$ 301,000$

Estimate is based on the latest manufacturers catalogue prices and engineering estimates using current costs for labor and material.

\section{Method of Accomplishment}

The engineering, procurement and quality assurance (at $\$ 24,000, \$ 162,000$, and $\$ 8,000$, respectively) will be accomplished by BNL. The procurement of materials and components will be accomplished with multiple orders of the fixed-price competitive type wherever possible. Installation and assembly will be carried out at the job site by BNL personnel. The work is considered "non-covered" work, not subject to the Davis-Bacon Act, Ref., DEAR 970-2273 (a) (3) (Research machinery and equipment, assembly, modifications, rearrangement and setup).

7. Schedule

Start $\quad$ Complete

Engineering

June, 1992 October, 1992

Procurement

October, 1992 July, 1993

Assembly, Installation, and Testing

July, 1993 December, 1993 


\begin{tabular}{|c|c|c|c|c|c|}
\hline $\begin{array}{l}\text { Power } \\
\text { Supply }\end{array}$ & $\begin{array}{l}\text { Beam } \\
\text { Momentum }\end{array}$ & $\begin{array}{l}\text { Snake } \\
\text { Angle } \\
\theta \mathrm{p}\end{array}$ & $\%$ Snake & $\mathrm{P}_{f} / \mathrm{P}_{i}$ & Comment \\
\hline $\begin{array}{ll}2.4 \mathrm{kA} \\
@ 40 \mathrm{~V}\end{array}$ & $\begin{array}{l}7.5 \mathrm{GeV} / \mathrm{C} \\
8.9 \\
10.0\end{array}$ & $\begin{array}{l}6^{\circ} \\
5^{\circ} \\
4.5^{\circ}\end{array}$ & $\begin{array}{l}3.3 \\
2.8 \\
2.5\end{array}$ & $\begin{array}{l}100 \% \\
93 \\
80\end{array}$ & $\begin{array}{l}\text { Cross } \mathrm{G}_{\gamma}=7-14,0+\nu \\
\text { Cross } \mathrm{G}_{\gamma}=7-17 \text {, transition } \\
\mathrm{G}_{\gamma}=24-\nu, 0+\nu ; \text { good choice } \\
\text { to start machine physics }\end{array}$ \\
\hline $\begin{array}{l}4.8 \mathrm{kA} \\
\text { @80 V }\end{array}$ & $\begin{array}{l}12.9 \mathrm{GeV} / \mathrm{C} \\
15.0 \\
18.0 \\
18.5\end{array}$ & $\begin{array}{l}7^{\circ} \\
6^{\circ} \\
5^{\circ} \\
4 \cdot 5^{\circ}\end{array}$ & $\begin{array}{l}3.9 \\
3.3 \\
2.8 \\
2.5\end{array}$ & $\begin{array}{l}100 \% \\
99.5 \\
83 \\
56\end{array}$ & $\begin{array}{l}\text { Cross additional } \\
\text { resonances. Study } \mathrm{G} \gamma=27 \& \\
36-\nu \text { interference. A } \\
\text { possible physics run at } \\
18.5 \mathrm{GeV} / \mathrm{c} \text { with about } 40 \% \\
\text { polarization. }\end{array}$ \\
\hline $\begin{array}{l}9.5 \mathrm{kA} \\
@ 120 \mathrm{~V}\end{array}$ & 22.5 & $7^{\circ}$ & 3.9 & $100 \%$ & $\begin{array}{l}\text { Machine studies. Physics } \\
\text { run. } 1.0 \text { sec rise time } \\
\text { instead of } 0.6 \mathrm{sec} \text {. at } 7^{\circ}\end{array}$ \\
\hline $7.1 \mathrm{kA}$ & & $6^{\circ}$ & 3.3 & 100 & $\begin{array}{l}\text { and back to } 0.6 \mathrm{sec} \text {. at } \\
5.5^{\circ} \text {. }\end{array}$ \\
\hline $6.5 \mathrm{kA}$ & & $5.5^{\circ}$ & 3.1 & 93 & \\
\hline
\end{tabular}

To go $24.8 \mathrm{GeV} / \mathrm{C}$ we need system upgrade to get $36+\nu$ correction pulse (Appendix 5).

\begin{tabular}{|c|c|c|c|c|c|}
\hline $\begin{array}{l}9.5 \mathrm{kA} \\
\text { a } 120 \mathrm{~V}\end{array}$ & 24.8 & $7^{\circ}$ & 3.9 & $50 \%$ & $\begin{array}{l}\text { RHIC injection energy. } \\
\text { Study transfer, extraction } \\
\text { and RHIC 1.4, sec rise } \\
\text { time. }\end{array}$ \\
\hline $\begin{array}{ll}11.2 \mathrm{kA} \\
@ 184 \mathrm{~V}\end{array}$ & 24.8 & $8^{\circ}$ & 4.4 & $90 \%$ & $\begin{array}{l}\text { RHIC operation with suf- } \\
\text { ficient voltage for } 0.6\end{array}$ \\
\hline $\begin{array}{l}12.5 \mathrm{kA} \\
\text { @2 } 205 \mathrm{~V}\end{array}$ & 24.8 & $9^{\circ}$ & 5.0 & $100 \%$ & sec. rise time. \\
\hline
\end{tabular}

*Note: $100 \%$ snake is a precession angle $\theta \mathrm{p}=180^{\circ}$.

There are $2.4 \mathrm{kA}$ and $4.8 \mathrm{kA}$ supplies in the AGS inventory. Two (2) 4.8 $\mathrm{kA}$ supplies in parallel can be used for $9.5 \mathrm{kA}$. New supplies probably needed for RHIC operation. 
Because of the phased start-up for the initial polarized beam facility, we configured our fast quad systems to reach only $23 \mathrm{GeV} / \mathrm{c}$. We did not set up for the $36+\nu$ resonance correction. We, therefore, now have to reconfigure our equipment so we can cross $\mathrm{G} \gamma=36+\nu$ and reach RHIC injection energy. The following table lists the shuffling that is needed where "OLD" is our original set up and "NEW" is what is necessary now.

\section{Fast Quad Modulator Upgrade}

\section{Present and Possible Phase 2 or 3 Configuration}

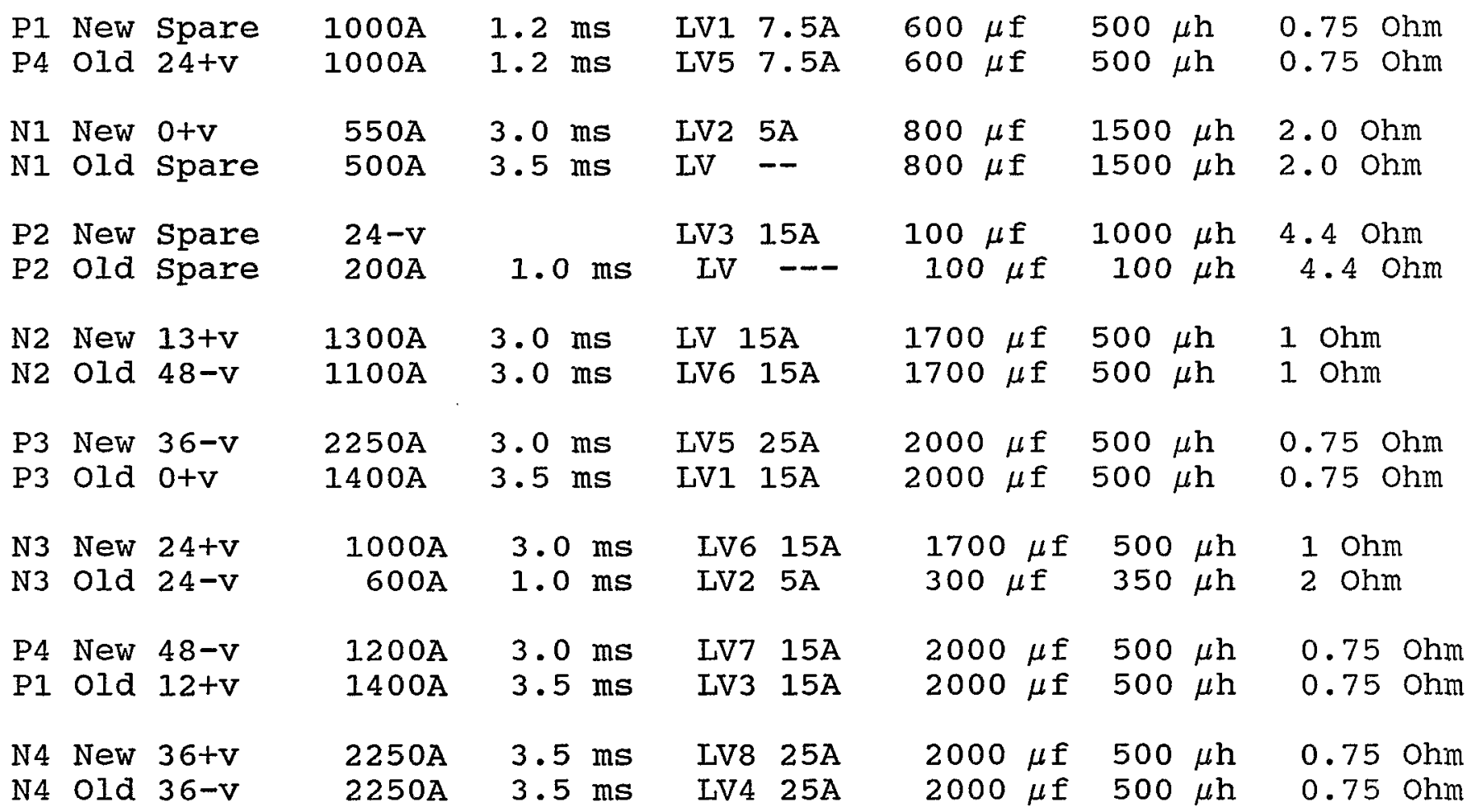




\section{MANPOWER REQUIREMENTS}

Reconfigure power supplies and cables in E-10 House:

1 Week, 2 Technicians $=2$ Man Weeks

Reconfigure pulses in 10 houses, change on ignitron, and add one ignitron 3 Weeks /hs, 2 Technicians = 60 Man Weeks

\section{HARDWARE REQUIREMENTS}

\begin{tabular}{lll} 
& $\begin{array}{l}\text { Unit } \\
\text { Price }\end{array}$ & $\underline{\text { Total }}$ \\
50 One Ohm Resistors & $\$ 30$ & $\$ 1,500$ \\
100 Resistor Clamps & $\$ 10$ & $\$ 1,000$ \\
$11500 \mu \mathrm{H}$ Inductors & $\$ 300$ & $\$ 3,300$ \\
$12500 \mu \mathrm{f}$ Capacitors & $\$ 800$ & $\$ 9,600$ \\
$24100 \mu \mathrm{f}$ Capacitors & $\$ 300$ & $\$ 7,200$ \\
12 Ignitrons & $\$ 1,500$ & $\$ 18,000$ \\
Misc. Cables/Clamps & $\$ 200 / \mathrm{hs}$ & $\$ 2,000$ \\
Ignitron Mounting Hardware & $\$ 100 / \mathrm{hs}$ & $\$ 1,000$ \\
\hline & & $\$ 43,600$
\end{tabular}

This allows us to get to $\mathrm{P}=26.4 \mathrm{GeV} / \mathrm{c}$ which was the original design goal for the AGS and, of course, to inject at RHIC energy of $24.87 \mathrm{GeV} / \mathrm{C}$. 


\section{APPENDIX 6}

\section{COST "GUESSTIMATE" FOR RHIC}

SNAKES AND POLARIMETERS

E.D. Courant and S.Y. Lee have presented a design for a split siberian Snake which can also function as a spin rotator and thus reduce the number of magnets necessary to preserve and rotate polarization in RHIC. Using split snakes then requires only two such devices per ring or 32 magnets for RHIC. A conceptual design of room-temperature magnets for such snakes has been made. A $2 \mathrm{M}$ long picture frame magnet at $13.75 \mathrm{KG}$ with a $1^{\prime \prime} \mathrm{V} \times 5^{\prime \prime} \mathrm{H}$ gap costs out at $\$ 50,000 /$ magnet. These are long magnets and $1 / 2 \mathrm{M}$ or $1 \mathrm{M}$ superconducting magnets should be considered. An estimate for a $1 / 2 \mathrm{M}, 3$ " diameter, 5.4T magnet has recently been made for the $200 \mathrm{GeV}$ SSC booster. This came to about $\$ 50,000$. A 5" diameter for RHIC would be more expensive, but power supplies would be cheaper. Costs appear to be competitive between room temperature and SC magnet systems. Available straight section length might be a decisive factor. There will be additional costs besides these to get an operational system.

4 Snakes (32 magnets)

Cabling \& Controls

Power Supplies

oulomb-Nuclear Interference

Polarimeter

Contingency, Engineering,

Quality control

TOTAL

$$
\begin{array}{rr}
\$ 1.6 & M \\
0.8 & M \\
0.7 & M \\
\hline \$ 3.1 & M
\end{array}
$$

$\$ 0.8 \mathrm{M}$

$\$ 3.9 \mathrm{M}$

$\$ 0.9 \mathrm{M}$

$\$ 4.8 \mathrm{M}$ 


\title{
APPENDIX 7
}

\section{PROPOSAL FOIR ACCELERATOR IMPROVEMENTS}

\author{
PARTIAI SIBERIAN SNAKE
}

\section{Basis}

The AGS accelerator must overcome depolarizing resonances in order to accelerate a polarized proton beam. The Siberian snake of this project allows this to be done in a very efficient manner.

\section{Description}

The partial siberian snake for this project will be a $4 \mathrm{~T}-\mathrm{M}$ room-temperature solenoid which will be built and installed in a 10-foot long AGS straight section. It will be connected to various existing power supplies which will supply currents from approximately $2 \mathrm{kA}$ to $9.6 \mathrm{kA}$ at $125 \mathrm{~V}$ or less as desired for various tests and programs. These will ramp the solenoid field currents synchronously with the AGS. The solenoid current will then be discharged through a bridge circuit on flattop in about $100 \mathrm{msec}$. The entire system will be interfaced to the Apollo control system in a similar manner to our existing pulsed magnets.

\section{Justification}

The AGS accelerator presently requires $2-3$ weeks of dedicated tune-up time in order to operate with an accelerated polarized proton beam. The partial siberian snake should allow this time to be reduced to 2-3 days and also to provide a beam with a much higher polarization for AGS experiments, as well as for injection into RHIC. A phased procedure allows the initial use of smaller power supplies which will extend the scope of accelerator research on snakes from the recent work at the Indiana University Cyclotron Facility. This research will be directly applicable to snakes in RHIC and SSC.

\section{Analysis of Safety and Pollution}

There are no potential pollution problems or explosion risks associated with this project, other than those common to high power electrical equipment installation. Fire hazards are also limited to the usual risks inherent with electrical cables and equipment. The electrical installation will be designed and installed to meet or exceed the current national standards and safety codes.

All work will be in accordance with DOE Order 5480.1B "Environmental Protection, Safety and Health Protection Standards", DOE 6430.1A, General Design Criteria Manual, and BNL's Safety Manual. 
5. Cost Estimate

A. Engineering a approximately 10\% of Procurements, Assembly,

$\$ 10,000$

Installation, and Testing

B. Procurements

$\begin{array}{lr}\text { Copper } & \$ 30,000 \\ \text { Steel } & 1,000 \\ \text { Fixtures + Central Tube } & 20,000 \\ \text { Misc. } & 5,000 \\ \text { Cables } & 5,000 \\ \text { Controls } & 10,000 \\ \text { Bridge Circuit } & 10,000\end{array}$

C. Assembly, Installation, Testing

$\$ 81,000$

D. Quality Assurance @ 3\% of Project Cost

$\$ 20,000$

$\$ 3,300$

E. Contingency a $10 \%$ of Project cost

$\$ 10,000$

TOTAL PROJECT COST

$\$ 124,300$

\section{Method of Accomplishment}

The engineering, procurement and quality assurance (at $\$ 10,000, \$ 81,000$, and $\$ 3,300$, respectively) will be accomplished by BNL. The procurement of materials and components will be accomplished with multiple orders of the fixed-price competitivetype wherever possible. Installation and assembly will be carried out at the job site by BNL personnel. The work is considered "non-covered" work, not subject to the Davis-Bacon Act, Ref. DEAR 970-2273 (a) (3). (Research machinery and equipment, assembly, modifications, rearrangement and setup).

7. Schedule

Engineering

Procurement

Assembly, Installation, Testing

\section{$\underline{\text { start }}$}

Jan. 1991

May 1991

July 1992
Complete

May 1991

March 1992

December 1992 